\title{
ÁREAS VERDES URBANAS E A LEGISLAÇÃO AMBIENTAL
}

\author{
Sarita Soraia de Alcântara Laudares ${ }^{1}$
}

\author{
Eva Costa de Barros ${ }^{2}$
}

\section{Luís Antônio Coimbra Borges³}

RESUMO: O novo Código Florestal estabeleceu em seu Art 25, inciso II, que as reservas legais ao serem inseridas no perímetro urbano possuem tutela jurídica para serem transformadas em Áreas Verdes Urbanas. Porém, a lei não definiu critérios de como proceder com atividades dentro dessas áreas, deixando-as passíveis de intervenções e ações anticonservacionistas. O presente trabalho tem com metodologia a pesquisa exploratória, bibliográfica e documental visando discutir e analisar a legislação no tocante a preservação das reservas legais transformadas em áreas verdes urbanas.

Palavras-chave: Reserva Legal. Tutela Jurídica. Código Florestal.

\footnotetext{
1 Discente de Mestrado em Ciências Florestais, Universidade Federal de Lavras. E-mail: saritalaudares@gmail.com.

2 Mestre em Ciências Florestais, Universidade Federal de Lavras. E-mail: barros_eva@yahoo.com.br

3 Engenheiro Florestal, Universidade Federal de Lavras, Professor Adjunto. E-mail: luis.borges@dcf.ufla.br.
} 


\section{INTRODUÇÃO}

A conservação de florestas e outros tipos de vegetação nativa é fundamental para proteger a fauna e a flora originais de cada região. A manutenção de fragmentos mesmo que pequenos, em propriedades rurais e urbanas garantem ainda que minimamente, o fluxo gênico das espécies e consequentemente a biodiversidade.

A legislação brasileira contém dentre os principais instrumentos para assegurar esta conservação, a Área de Preservação Permanente (APP) e a Reserva Legal (RL). As APPs correspondem áreas protegidas, cobertas ou não por vegetação nativa cuja função ecológica é preservar os recursos hídricos, a paisagem, a estabilidade geológica, a biodiversidade, a fauna e a flora, bem como proteger o solo e garantir o bem estar da população que desse bem se aproveita. Já a $\mathrm{RL}$, corresponde a área localizada no interior de uma propriedade ou posse rural com função de assegurar o uso socioeconômico sustentável dos recursos naturais do imóvel rural, bem como auxiliar a conservação e reabilitação dos processos ecológicos, promovendo a conservação da biodiversidade (BRASIL, 2012).

As necessidades da sociedade, a expansão urbana atingindo o meio rural, o crescimento populacional, e a expansão dos municípios, resultaram em novas demandas da sociedade, e com isso, um novo arranjo jurídico foi formulado para atender a conservação ambiental e garantir qualidade de vida à sociedade. Um aspecto evolutivo da Legislação Ambiental brasileira se deu com a edição do novo Código Florestal Lei Federal ํo 12.651/2012, onde as reservas legais que foram incluídas em perímetros urbanos foram contempladas com a proteção ambiental através da figura das Áreas Verdes Urbanas.

Nos centros urbanos as principais áreas de conservação são as áreas verdes. Estas podem apresentar ao homem nas cidades benefícios, como citam alguns autores, dentre eles Cavalheiro \& Del Picchia (1992), Lima et al. (1994), Henk-Oliveira (1996), Nucci (2001), Vieira (2004), Toledo \& Santos (2008), Caporusso \& Matias (2008): proteção das nascentes e dos mananciais, aumento do conforto ambiental, abrigo à fauna e flora, controle da poluição do ar e acústica, estabilização de superfícies por meio da fixação do solo pelas raízes das plantas, equilíbrio do índice de umidade no ar, organização e composição de espaços no desenvolvimento das atividades humanas, 
valorização visual e ornamental do ambiente, recreação, diversificação da paisagem construída, dentre outros.

O inciso II do art. 25 da lei $n^{\circ} 12.651 / 12$ estabelece a possibilidade dos municípios firmarem essa proteção ambiental através da transformação de Reservas Legais em áreas verdes nas expansões urbanas. Há, entretanto, a necessidade de medidas para melhor disciplinar as ações anti-conservacionistas proporcionadas pelas brechas da Lei.

O objetivo do presente trabalho é discutir e analisar a legislação no tocante a preservação das reservas legais transformadas em áreas verdes urbanas, quando as propriedades são incluídas nas expansões urbanísticas conforme o inciso II do art. 25 da lei $n^{\circ} 12.651 / 12$.

\section{DESENVOLVIMENTO}

\subsection{METODOLOGIA}

Gil (2010) sugere a classificação das pesquisas segundo seus objetivos mais gerais. Nesse contexto, esse trabalho constitui uma pesquisa exploratória. Como afirmam Collis \& Hussey (2005), o foco é obter insights e familiaridade com a área do assunto para investigação mais rigorosa num estágio posterior. Técnicas típicas usadas em pesquisa exploratória incluem estudos de caso, observação e análise histórica.

Em decorrência do ambiente de pesquisa, da abordagem teórica e das técnicas de coleta e análise de dados, é possível definir o delineamento mais pertinente para cada pesquisa (GIL, 2010). Analisando os delineamentos proposto pelo autor, os mais adequados ao presente trabalho são: pesquisa documental e bibliográfica.

Tanto a pesquisa bibliográfica quanto a documental, se baseiam em material já publicado, sendo a diferença principal entre elas a natureza das fontes. A pesquisa bibliográfica fundamenta-se em material elaborado por autores com propósito específico de ser lido por públicos específicos. Já a pesquisa documental vale-se de materiais elaborados com finalidades diversas tais como autorização, comunicação, atos jurídicos. 
Para subsidiar a elaboração da pesquisa bibliográfica, foram coletados dados basicamente de periódicos científicos; livros de obras científicas ou técnicas; teses e dissertações; anais e encontros científicos em bibliotecas convencionais e meio eletrônicos. Para documental foram utilizados: documentos jurídicos como leis; resoluções e normativas; documentos institucionais mantidos em arquivos públicos.

\subsection{RESULTADOS E DISCUSSÃO}

O Direito ambiental surge como instrumento através do qual, o Estado programa políticas públicas traduzidas em ações, afim da defesa dos recursos naturais. $O$ atual Código Florestal Brasileiro, instituído pela Lei $n^{\circ} 12.651 / 12$, foi editado há quarenta e seis anos com a Lei $n^{\circ} 4.771 / 65$ que revogava a primeira legislação ambiental em 1934, instituída pelo Decreto ${ }^{\circ}$ 23.793. Ao analisar o histórico da legislação florestal, pode-se observar que todas as mudanças ocorridas visavam alicerçar a proteção das áreas nativas brasileiras, chegando alcançar a instituição das Áreas de Proteção Permanente e Reserva Legal.

Tendo em vista a importância dessas áreas, surge a necessidade de formalização da proteção das Reservas Legais na hipótese de inserção do imóvel em zona urbana. Devido ao acelerado processo de urbanização que o Brasil vem sofrendo desde o século passado, as propriedades rurais estão sendo transformadas em urbanas e com isso, como já alertava Souto (2010), como ficaria a situação das áreas de RL? O mesmo autor comenta sobre a obrigatoriedade de implantação de Áreas Verdes, mesmo não estando expressa em norma própria.

O novo Código Florestal inovou ao acrescentar uma seção (III) sobre o Regime de proteção das Áreas Verdes Urbanas. Neste segmento está inserido o Art. 25, pelo qual fica instituído que o poder público municipal contará com quatro instrumentos para estabelecimento dessas áreas, dentre eles, a transformação das $\mathrm{RL}$ em áreas verdes nas expansões urbanas (inciso II). Por um lado, resolve-se a questão das Reservas Legais, quando as propriedades que a detém são incorporadas ao perímetro urbano, por outro, 
percebe-se que não há nenhum mecanismo, critério ou técnica para utilização sustentável dessas áreas a serem protegidas.

Assim como as Reservas Legais nas zonas rurais, as áreas verdes são de suma importância para conservação dos recursos naturais. Além de aumentar área permeável para absorção de águas e conectar paisagens, aumenta o número de espécies da fauna que se utilizam da vegetação com habitat. De acordo com Antunes e Figueiró (2011), se as Áreas Verdes forem reduzidas, consequentemente as espécies existentes não conseguirão expandir horizontalmente por não terem corredores biológicos que possuem a função de conservação e aumento da biodiversidade.

Após um levantamento bibliográfico sobre a influência dessas áreas verdes na área urbana, constatou-se que os locais onde havia maior número de fragmentos de áreas verdes, maior era a diversidade de animais, que de alguma maneira dependiam daquele habitat.

Neto (2011), por exemplo, mapeou e caracterizou o município de São Lourenço para discutir a mastofauna ocorrente em relação às unidades mapeadas. $O$ autor verificou uma maior riqueza de biodiversidade de diversificação da mastofauna naqueles locais onde havia presença de fazendas ou áreas verdes. Constatou que em áreas construídas, esta mastofauna diminuía a diversificação, ou seja, que a presença de áreas verdes mesmo que, em capões e terrenos baldios foi capaz de abrir nichos favoráveis e promover uma diversificação da fauna urbana. Com isto, observou-se a importância destas áreas diante dos centros urbanos, e a necessidade de projetos que tenham como objetivo a implementação de mais áreas verdes e um manejo adequado.

Julião et al. (2005), realizaram uma pesquisa sobre insetos galhadores associados a duas espécies de plantas invasoras de áreas urbanas e peri-urbanas na região metropolitana de Belo Horizonte. Verificou-se alguns espaços como prédios, casas, favelas, áreas verdes urbanas e rurais, dentre outros resultados, saber se a diversidade de insetos era influenciada pelas características físicas dos espaços urbanos. Constatouse que não houve diferença de riqueza, mas que em áreas que possuíam unidades verdes, havia maior abundância de insetos, e aumentava à medida que se caminhava rumo as áreas rurais. 
Taura e Laroca (2001), em um estudo mais complexo, também encontraram grande diversidade de abelhas em ambientes urbanos que continham áreas verdes, mas que isso também dependia das espécies da fauna existente naquela região.

Como ultimo exemplo, Brun, Link e Brun (2007), analisaram através de uma revisão literária o emprego da arborização na manutenção da biodiversidade urbana e constataram que o "ambiente árvore" foi positivo naquelas áreas que a continham, pois serviram como complemento de fontes alimentares as espécies típicas de matas nativas e mantiveram a manutenção da biodiversidade. Além disso, destacaram a importância da conexão das árvores nas áreas verdes para aumentar fluxo gênico e consequente diversidade. E alertaram para o cuidado ao escolher as espécies pois poderia simplificar a fauna que ali circunda ou habita.

Ao refletir a importância e influência que estas áreas verdes possuem em relação à diversificação e riqueza da fauna e flora, questiona-se a falta de mecanismos legais que estabeleçam padrões de planejamento e ordenação das atividades urbanas dentro dessas áreas verdes, visando garantir uma cobertura vegetal nativa mínima, e com isso, a conservação da biodiversidade, através da formação de corredores ecológicos e criação de habitats para espécies vegetais e animais.

\section{CONCLUSÃO}

O novo Código Florestal instituiu a obrigatoriedade aos municípios de transformarem as Reservas Legais em Áreas Verdes Urbanas, quando as propriedades rurais forem inseridas nos perímetros Urbanos. Desta forma, aquelas áreas nativas que antes não poderiam ser desmatadas ou utilizadas sem o manejo sustentável, continuarão sob proteção ambiental através da figura das Áreas Verdes Urbanas. No entanto, na lei não consta como estas áreas devem ser manejadas e utilizadas, de modo a minimizar os impactos negativos causados pela vizinhança urbana. Faz-se necessária a criação de normas ou decretos para suprimir ações anti-conservacionistas proporcionadas pelas brechas da Lei. 


\section{AGRADECIMENTOS}

Ao Núcleo de Estudos em Pesquisa e Planejamento Ambiental (NEPPA) da Universidade Federal de Lavras (UFLA) pelo apoio técnico-científico e ao CNPq, FAPEMIG e CAPES pelo apoio financeiro.

\section{REFERÊNCIAS}

ANTUNES, L.S.; FIGUEIRÓ, A.S. O mapeamento de biótopos como ferramenta para identificação de conflitos ambientais: um estudo de caso na cidade de Santa Maria-RS. Revsbau, Piracicaba, SP, v.6, n.2, p.1-21, 2011.

BRASIL. Lei 12.651, de 25 de maio de 2012. Dispõe sobre a proteção da vegetação nativa. Brasília, 2012. Disponível em <http://www.planalto.gov.br > Acesso em: 27 out. 2012.

BRUN, F. G. K.; LINK, D.; BRUN, E. J. O emprego da arborização na manutenção dabiodiversidade defauna em áreas urbanas. Revista da sociedade brasileira de arborização urbana, v.2, n.1, p.117-127, 2007.

CAPORUSSO, Danúbia; MATIAS, Lindon Fonseca. Áreas verdes urbanas: avaliação e proposta conceitual. In: SEMINÁRIO DE PÓS-GRADUAÇÃO EM GEOGRAFIA DA UNESP, 8., 2008, Rio Claro. Anais... Rio Claro, 2008.

CAVALHEIRO, F.; DEL PICCHIA, P.C.D. Áreas verdes: conceitos, objetivos ediretrizes para o planejamento. In: CONGRESSO BRASILEIRO SOBRE ARBORIZAÇÃO URBANA, 1. e ENCONTRO NACIONAL SOBRE ARBORIZAÇÃO URBANA, 4., 1992, Vitória. Anais... Vitória, 1992. p.29-38.

COLLIS, J.; HUSSEY, R. Pesquisa em administração: um guia prático para alunos de graduação e pós-graduação. Trad. Lucia Simonini. 2. ed. Porto Alegre: Bookman, 2005.

GIL, A. C. Como elaborar projetos de pesquisa. 5. ed. São Paulo: Editora Atlas S.A. 2010. 
HENKE-OLIVEIRA, C. Planejamento ambiental na cidade de São Carlos (SP) com ênfase nas áreas públicas e áreas verdes: diagnóstico e propostas. 1996. $181 \mathrm{f}$. Dissertação (Mestrado em Ecologia) - Universidade Federal de São Carlos, São Carlos, SP.

JULIÃO, G. R. et al. Insetos galhadores associados a duas espécies de plantas invasoras de área urbana e peri-urbana. Revista Brasileira de Entomologia, v.49, n.1, p.97-106, 2005.

LIMA, A. M. L.P; CAVALHEIRO, F.; NUCCI, J.C.; SOUSA, M.A.L.B.; FIALHO, N. DEL PICCHIA, P.C.D. Problemas de utilização na conceituação de termos como espaços livres, áreas verdes e correlatos. In: CONGRESSO DE ARBORIZAÇÃO URBANA, 2., 1994, São Luis. Anais... São Luis, 1994, p.539-553.

METZGER, J. P.. Bases biológicas para a definição de Reservas Legais. Ciência Hoje, v.31, n.183, p.48-49, 2002.

NETO, R. M. Biótopos urbanos em São Lourenço (MG) e mastofauna silvestre associada. In: CONGRESSO DE ECOLOGIA DO BRASIL, 10., 2011, São Lourenço. Anais... São Lourenço, 2011.

NUCCI, J.C. Qualidade ambiental e adensamento urbano. Humanitas, São Paulo - SP, 2001. $142 \mathrm{p}$.

SOUTO, L. E. C. de O. A perpetuidade da reserva legal em zona urbana e seu aproveitamento como área verde. Jus Navigandis. Disponivel em: <http://jus2.uol.com.br/doutrina/texto.asp?id=15095>. Acesso em: 12 set. 2013.

TAURA, H. M.; LAROCA, S. BARBOSA, J. F., RODRIGUES, J. Melissocenótica (Hymenoptera, Anthophila) no Parque Florestal dos Pioneiros,Maringá, PR. (sul do Brasil) - I. Abundância relativa e diversidade. Acta Biol. Par., Curitiba, v.36, n.1-2, p.47-65, 2007.

TOLEDO, F.S; SANTOS, D.G. Espaços Livres de Construção. Revista da Sociedade Brasileira de Arborização Urbana, Piracicaba, SP, v.3, n.1, p.73-91, 2008. 
VIEIRA, P. B. H. Uma visão geográfica das áreas verdes de Florianópolis, SC: estudo de caso do Parque Ecológico do Córrego Grande (PECG). 2004. Trabalho de Conclusão de Curso - Universidade Federal de Santa Catarina, Florianópolis, SC. 